\title{
Case Report: Children with Severe Nutritional Rickets in the Naga Region in Northwest Myanmar, on the border with India
}

\author{
Hein Aung, ${ }^{1}$ Kyaw Soe, ${ }^{2}$ Frank F. Smithuis, ${ }^{3}$ Thomas Lamb, ${ }^{2}$ Moe Wint Aung, ${ }^{4}$ and Frank M. Smithuis ${ }^{1,2 *}$ \\ ${ }^{1}$ Medical Action Myanmar, Yangon, Myanmar; ${ }^{2}$ Myanmar Oxford Clinical Research Unit, Yangon, Myanmar; ${ }^{3}$ Department of Radiology, \\ Amsterdam UMC Imaging Center, Amsterdam, The Netherlands; ${ }^{4}$ Department of Endocrinology, Yangon General Hospital, Yangon, Myanmar
}

\begin{abstract}
Rickets is an often-neglected, painful, and disabling childhood condition of impaired bone mineralization. In this case series we describe a cluster of 29 children with severe, painful bone deformities who live in the very remote region of Nagaland in northwest Myanmar. Children were found to have low 25-hydroxyvitamin D, elevated parathyroid hormone, and elevated alkaline phosphatase levels, consistent with nutritional rickets secondary to vitamin $D$ deficiency, calcium deficiency, or a combination of the two. After treatment with vitamin $\mathrm{D}_{3}$ and calcium carbonate, significant improvement was seen in symptoms, biochemistry, and radiography. This is the first report of nutritional rickets in Myanmar in more than 120 years. Vitamin D and calcium supplementation, and food fortification for pregnant women and young children may be required to prevent this potentially devastating disease.
\end{abstract}

\section{INTRODUCTION}

Rickets is a disabling childhood condition that results from impaired bone mineralization at the growth plates. It is characterized by skeletal deformity, stunted growth, bone pain, and muscle weakness. ${ }^{1}$ Untreated rickets can result in failure to thrive, developmental delay, lifelong skeletal deformity, obstructed labor, and osteomalacia. ${ }^{1,2}$ Vitamin D deficiency and/or calcium deficiency are the most common causes of rickets. ${ }^{3}$ Vitamin D deficiency is often the result of insufficient sunlight exposure in combination with inadequate vitamin $D$ intake. Although insufficient sun exposure is not expected in (sub-) tropical countries, it can be caused by particular sociocultural or religious behaviors. ${ }^{4}$ In Yangon, the commercial capital of Myanmar, vitamin D insufficiency $(<50 \mathrm{nmol} / \mathrm{L})$ was reported in 49 of $60(82 \%)$ health-care workers (M. W. Aung, personal communication). However, this was attributed to a habit of sun avoidance for aesthetic purposes as a pale skin is considered desirable. Children in rural areas are generally expected to have sufficient sun exposure. Inadequate vitamin $\mathrm{D}$ intake can be caused by maternal vitamin $\mathrm{D}$ deficiency, exclusive breastfeeding, and a vitamin D-poor diet (vegetarian and/or lack of vitamin D-enriched food). ${ }^{5}$ Calcium deficiency is caused predominantly by poor access to dietary products after weaning. We report a cluster of children with severe rickets in Nagaland, northwest Myanmar.

\section{CASE REPORT}

Medical Action Myanmar (MAM) is a medical aid organization that provides basic medical care to 275 villages in Nagaland, a remote mountainous region in the far northwest of Myanmar, on the border with India. In January 2019, MAM mobile medical teams identified 29 children in nine villages in Nanyun township (lat. $27^{\circ} \mathrm{N}$ ) with painful joints, walking difficulties, and knee and wrist joint deformities clinically consistent with rickets (Figure 1).

\footnotetext{
*Address correspondence to Frank M. Smithuis, 32a1 Kokkine Swimming Club Lane, Bahan 11201, Yangon, Myanmar. E-mail: frank.m.smithuis@gmail.com
}

The children had a median age of 6 years (interquartile range [IQR], 5-8 years). Twelve of the 29 children had a first-degree relative included in the case series. All but one patient complained of joint pain and walking difficulty that started at a median age of 3 years (IQR, 2-4 years). Leg deformity (genu valgum, $72 \%$; genu varum, $28 \%$ ), antalgic gait (86\%), and wrist enlargement $(75 \%)$ were the most common abnormalities. Three patients (10\%) were unable to walk. Other deformities included pectus carinatum (62\%), rachitic rosary (17\%), and teeth abnormalities (31\%) (Table 1). Most patients were stunted (27 of 29, 93\%) (Figures 2 and 3) and underweight (15 of $21,71 \%)$. Ten of 25 children started walking after 18 months of age. Patients reported a diet composed primarily of rice, grains, and leafy vegetables, without food rich in vitamin D and/or calcium, such as fish, eggs, or milk products. Meat was consumed only rarely, after successful hunting. Fortified food was absent. Children did not avoid sun exposure unless their mobility was severely limited.

Serum biochemistry demonstrated a low 25-hydroxyvitamin D (25OHD) level of $<30 \mathrm{nmol} / \mathrm{L}$ in 22 of $29(76 \%)$ children, a high parathyroid hormone PTH) level of $>65 \mathrm{pg} / \mathrm{mL}$


FIGURE 1. Photographs of children demonstrating typical features of genu valgus, genu varum, wrist swelling, and rachitic rosary before treatment. 

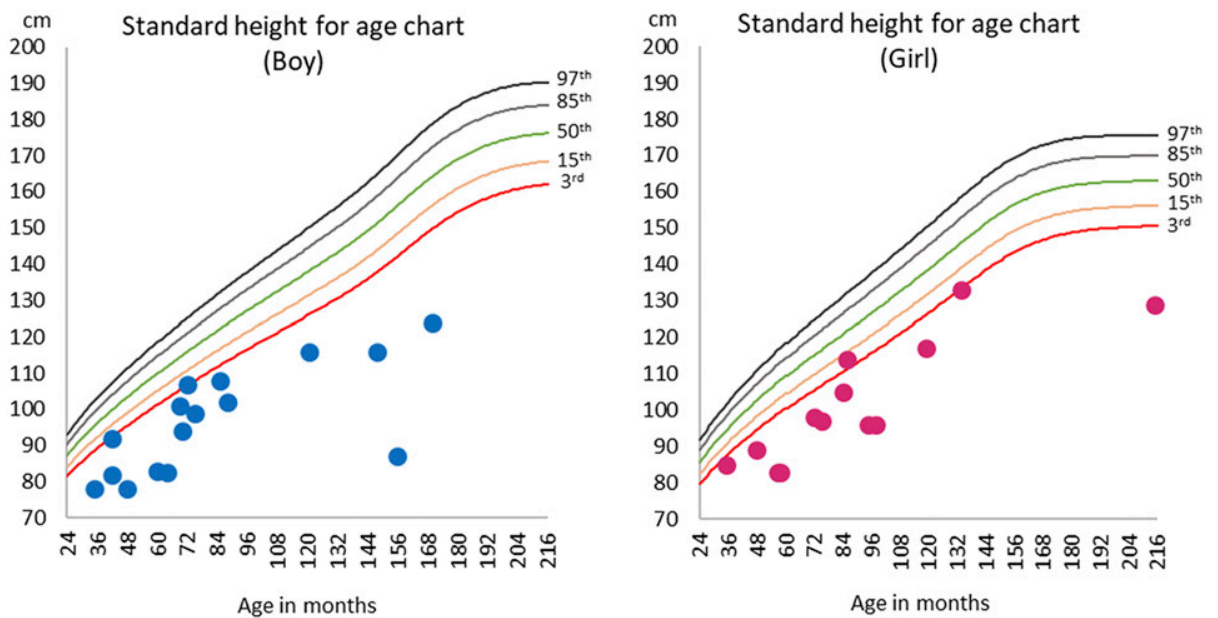

FIGURE 2. Standard child height-for-age charts, differentiated for girls and boys. The red and blue dots represent observed patient data at baseline.

in 22 of $28(79 \%)$ children, and an elevated alkaline phosphatase (ALP) level of $>800$ UL in 28 of 29 children $(97 \%)$. Fourteen children (48\%) had low serum phosphate levels and six (21\%) had low serum calcium levels (Table 2). Nonfasted venous blood samples were kept between 2 and $8^{\circ} \mathrm{C}$, and were analyzed within 48 hours at a laboratory in Yangon. Serum concentrations of $25 \mathrm{OHD}$ and $\mathrm{PTH}$ were calculated using an electrochemiluminescence immunoassay (Roche cobas e411 analyzer, Roche Diagnostics International, Rotkreuz ZG, Switzerland).

Because of the extreme remoteness of the children's location, X-ray examination performed at the Township hospital was limited to five children. X-rays illustrated diffuse osteopenia, widening of the metaphyseal growth plates with sclerosis, hypertrophic growth plates, and bowing of the diaphyses (Figure 4).

A diagnosis of nutritional rickets with low 250HD was made and the children were administered vitamin $D_{3}$ (a loading dose of $100,000 \mathrm{IU}$, followed by $5,000 \mathrm{IU} / \mathrm{d}$ for 2 months and then 1,000 IU/d for 10 months) plus calcium carbonate $(750 \mathrm{mg} / \mathrm{d}$ for children with a bodyweight of $10-19 \mathrm{~kg}$ and $1,500 \mathrm{mg} / \mathrm{d}$ for children $\geq 20 \mathrm{~kg}$ for 2 months, followed by $500 \mathrm{mg} / \mathrm{d}$ for all). The children were monitored every 2 to 3 months for 12 months. At 12 months, the children reported improved joint pain and mobility (93\% and $96 \%$, respectively). Two of 3 children who could not walk at all before, were able to walk. The third child had malunion and nonunion fractures at an early age and still could not walk. Considerable improvement was seen in biochemistry (Table 2 and Figure 5) and in radiography, in the five children who had undergone serial radiography (Figure 4). There was a significant improvement in height-for-age z-score: from -3.89 at baseline to -3.20 at 12 months (Wilcoxon's signed rank test, $P<0.0001$ ) (Figure 3 ).

\section{DISCUSSION}

We describe a cluster of children with rickets who presented with severe, disabling symptoms and skeletal deformities; and low 25OHD, raised PTH, and raised ALP levels consistent with calcipenic rickets. Treatment with vitamin $D_{3}$ and calcium carbonate resulted in considerable symptomatic, biochemical, and radiological improvement.

These children are the first reported cases of rickets in Myanmar for 120 years, following only a description of rickets in 19th-century Burma. ${ }^{6}$ In the neighboring countries of Bangladesh and India, rickets has been described repeatedly, with varying etiological factors depending on age and geographic location. Rickets in Bangladesh is more common after 2 years of age, and calcium deficiency is thought to be the primary etiological factor in the context of poor vitamin

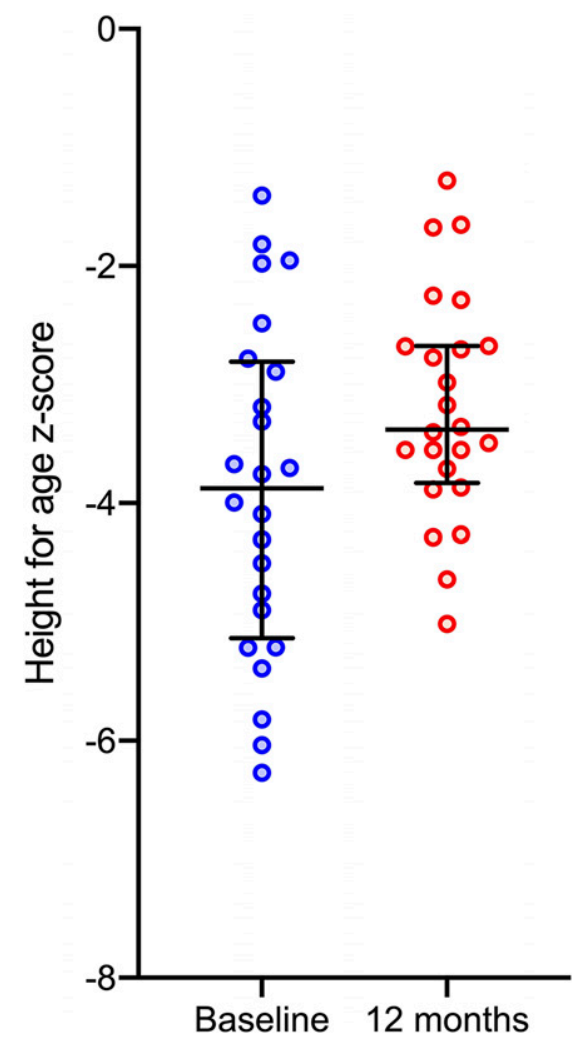

FIGURE 3. Height-for-age z-score for children at baseline and at 12month follow-up, with the median (bar) and interquartile range (capped bars). 


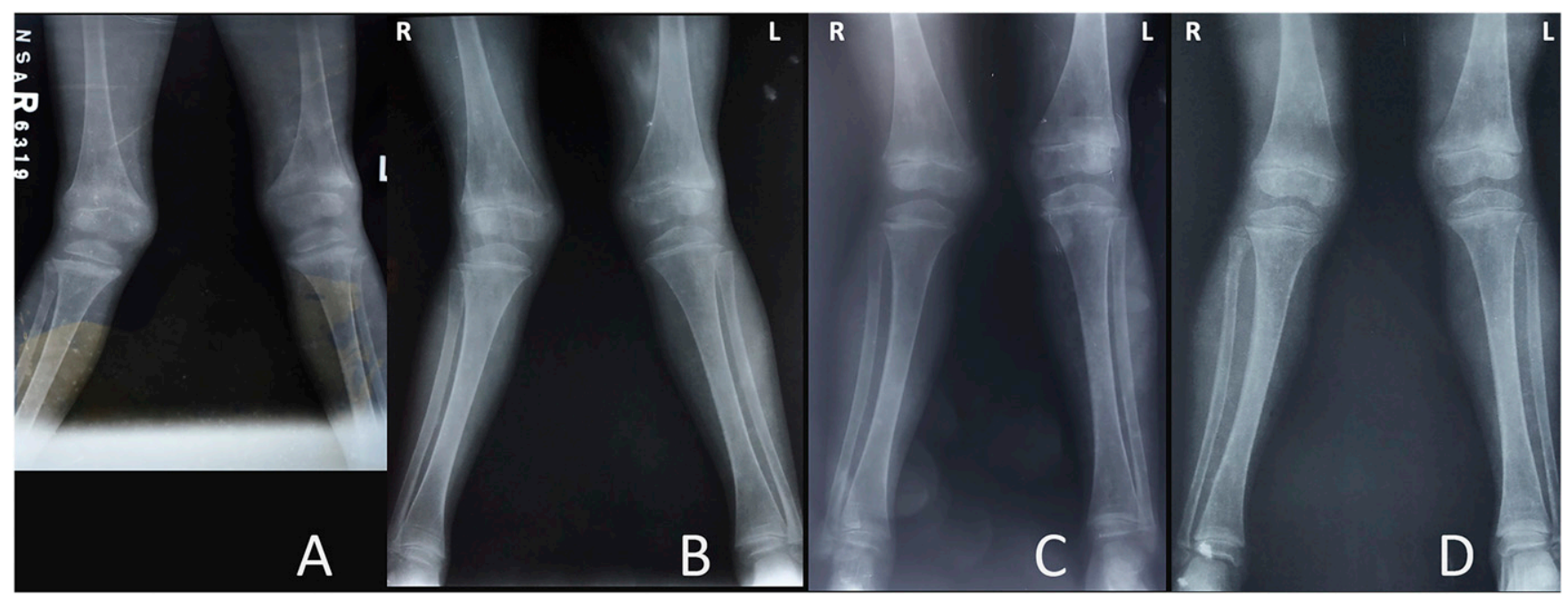

FIGURE 4. X-rays of a 6-year-old girl. (A) Pre-treatment X-ray shows severe widening/cupping of the metaphyseal growth plates with sclerosis, hypertrophic growth plates, bowing of the diaphyses, and diffuse osteopenia. (B-D) Post-treatment X-rays show a gradual straightening of the diaphysis, reduction in sclerosis at the epiphyses, and normalization of the distance between the distal metaphyses and epiphyses over time.

D status. ${ }^{7-9}$ In north India, dietary calcium deficiency was identified as the cause of rickets among young children $(<10$ years), whereas rickets among adolescent girls was caused by vitamin $D$ deficiency. ${ }^{10}$ In another study in north India, children (age, 6 months -5 years) with rickets experienced a better response after a combination of vitamin D plus calcium compared with vitamin $D$ or calcium alone, indicating that a combination of vitamin $\mathrm{D}$ and calcium deficiency was causing rickets. ${ }^{11}$ In the tea plantations of east Assam, northeast India, close to the Naga region in Myanmar, of 16,274 screened children age 1 to 18 years, $44(0.27 \%)$ had skeletal deformities consistent with nutritional rickets. ${ }^{12}$ Causative factors of rickets were not reported.

In Myanmar, it is generally assumed that ultraviolet $B$ radiation is adequate to prevent vitamin D deficiency. However, the diet of the people in Naga is based predominantly on rice,

TABLE 1

Demographic and clinical findings $(N=29)$

\begin{tabular}{lc}
\hline \multicolumn{1}{c}{ Characteristics } & Data \\
\hline Demographics & $6(5-8)[3-17]$ \\
Age at diagnosis, y; median (IQR) & \\
[range] & $3(2-4)[2-15]$ \\
Age at onset, y; median (IQR) [range] & $16(55.2)$ \\
Male, $N$ (\%) & $13(44.8)$ \\
Female, $N(\%)$ & $12(41.4)$ \\
First-degree family relative with rickets, & \\
$N(\%)$ & \\
Clinical findings, $N$ (\%) & $9(24)$ \\
Joint tenderness of knee, ankle, or wrist & $5(17)$ \\
Bossing of the skull & $9(31)$ \\
Dental deformity & $22(75)$ \\
Wrist enlargement & $18(62)$ \\
Pectus excavatum or pectus carinatum & $5(17)$ \\
Rachitic rosary & $2(6)$ \\
Kyphosis & $29(100)$ \\
Leg deformity & $21(72)$ \\
Genu valgum & $8(28)$ \\
Genu varum & $25(86)$ \\
Antalgic gait & $3(10)$ \\
Unable to walk &
\end{tabular}

grains, and leafy vegetables, and appears to be very low in vitamin D. Pregnant and lactating women in these communities could be vitamin $D$ deficient. Breast milk contains very little vitamin $D$, and in the absence of vitamin $D$ supplementation, prolonged breastfeeding (median duration, 20 months in this case series) likely contributed to low vitamin $D$ levels in infants. ${ }^{13}$ The mountainous Naga region is often shrouded in clouds and sunlight is among the lowest in the country (Figure 6). ${ }^{14}$ Naga children do not habitually avoid sun unless their mobility is restricted. As several children reported a late start in walking, limited ultraviolet exposure may have played a contributing factor to vitamin D deficiency. After breastfeeding, the typical diet was low in vitamin $D$ and calcium, and high in phytates. Calcium deficiency could be a causative factor, in combination with vitamin D deficiency or on its own. This could explain the late onset of recognized symptoms, at 3 years of age, after the start of weaning. The age of onset was

TABLE 2

Biochemical findings at baseline and after treatment with vitamin $D_{3}$ and calcium carbonate.

\begin{tabular}{|c|c|c|c|}
\hline Biochemical tests & $\begin{array}{l}\text { Pre-treatment } \\
(N=29), \\
\text { median (IQR) }\end{array}$ & $\begin{array}{l}\text { Post-treatment } \\
(N=25), \\
\text { median (IQR) }\end{array}$ & $\begin{array}{c}\text { Non- } \\
\text { parametric } \\
\text { Mann- } \\
\text { Whitney } \\
\text { test } P \text { value }\end{array}$ \\
\hline $\begin{array}{l}\text { Serum 25OHD; } \\
\text { normal range, } \\
>30 \mathrm{nmol} / \mathrm{L}\end{array}$ & $22.4(13.8-29.9)$ & $80.0(53.7-98.7)$ & $<0.0001$ \\
\hline $\begin{array}{l}\text { Plasma PTH; } \\
\text { normal range, } \\
15-65 \mathrm{pg} / \mathrm{mL}\end{array}$ & $122.9(71.5-223.6)$ & $31.1(18.6-52.7)$ & $<0.001$ \\
\hline $\begin{array}{l}\text { Serum ALP; } \\
\text { normal range, } \\
<800 \text { UL }\end{array}$ & $1,956(1,204-2,892)$ & $888(794-1,034)$ & $<0.001$ \\
\hline $\begin{array}{l}\text { Serum phosphate; } \\
\text { normal range, } \\
1.29-2.26 \mathrm{nmol} / \mathrm{L}\end{array}$ & $1.34(1.06-1.50)$ & $1.22(1.12-1.36)$ & 0.396 \\
\hline $\begin{array}{l}\text { Serum calcium; } \\
\text { normal range, } \\
2.00-2.50 \mathrm{nmol} / \mathrm{L}\end{array}$ & $2.15(2.05-2.29)$ & $2.30(2.19-2.39)$ & 0.004 \\
\hline
\end{tabular}



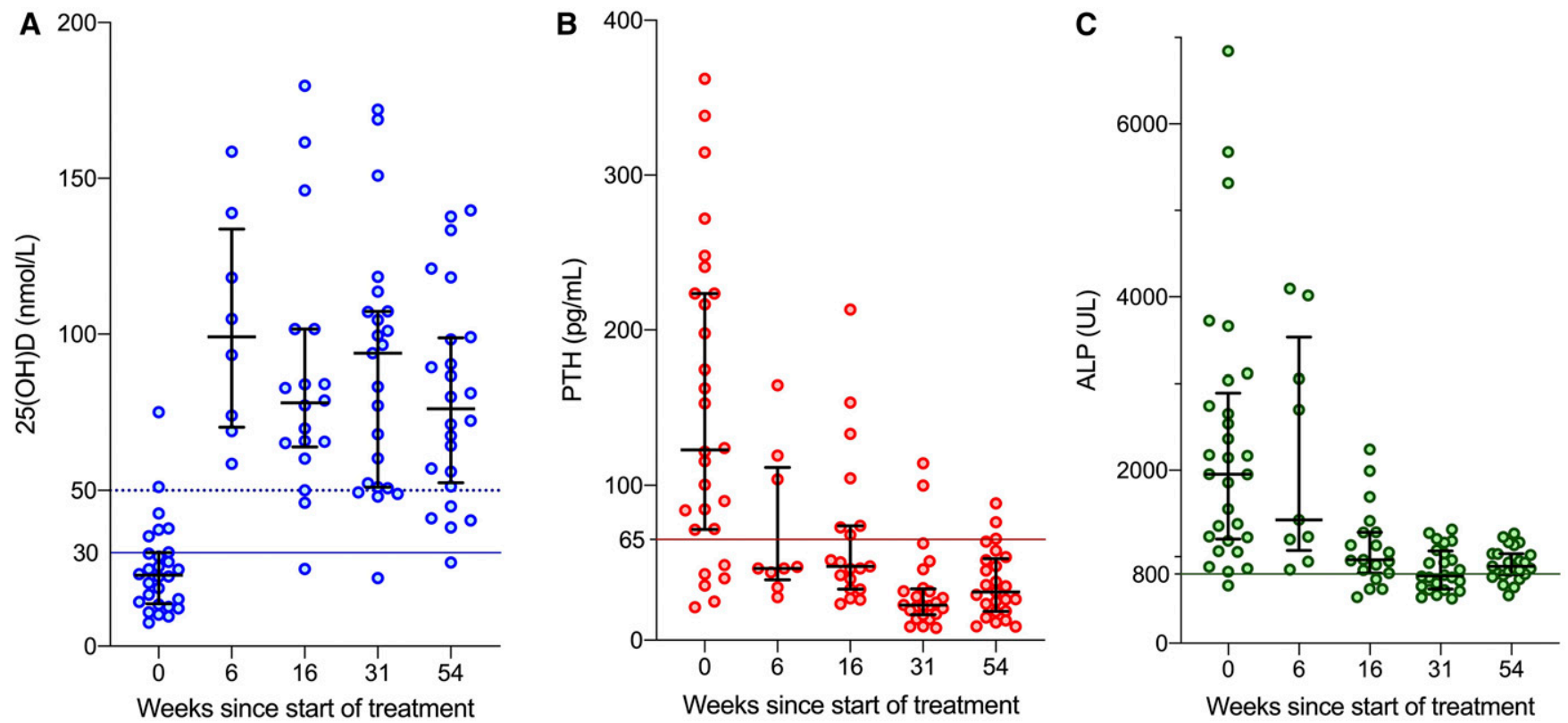

Figure 5. (A) Serum 25-hydroxyvitamin D (25(OH)D; blue) values at presentation and at follow-up after 1 year. (B) Parathyroid (PTH; red) values at presentation and at follow-up after 1 year. (C) Alkaline phosphatase (ALP; green) values at presentaTtion and at follow-up after 1 year. Individual patient values (small circles) are shown, along with median (bar) and interquartile range (capped bars). The dotted horizontal line in (A) on the $y$ axis represents the lower limit of normal $(50 \mathrm{nmol} / \mathrm{L})$ and the continuous line on $y$ axis represents the upper limit of depletion $(30 \mathrm{nmol} / \mathrm{L})$. The continuous lines in (B) and (C) represent the upper limit of normal range for PTH $(65 \mathrm{pg} / \mathrm{mL})$ and ALP (800 UL), respectively. Note that not all children had serum sampling at each follow-up.

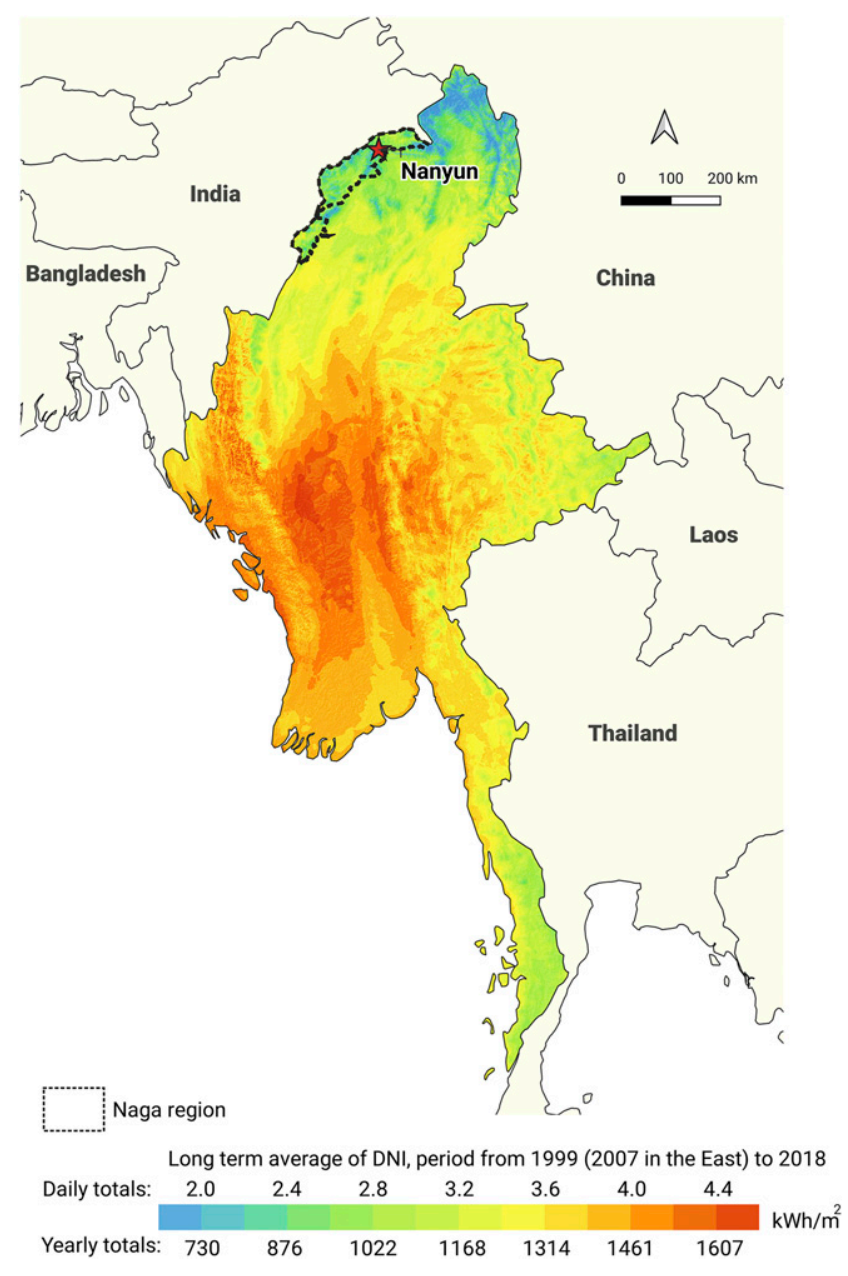

FIGURE 6. Direct normal irradiation in Myanmar. Long-term average of yearly totals. ${ }^{14}$ similar to a study conducted in southeast Bangladesh, where rickets was predominantly the result of a dietary calcium deficiency in the context of a chronically low vitamin D status. ${ }^{10}$ However, the serum calcium levels of the Bangladeshi children with active rickets were less than in our cohort, possibly suggesting an alternative etiology. ${ }^{10}$

We acknowledge the limitations inherent to case series study design. Additional limitations of this study include the limited access to radiography, remote laboratory analysis, and lack of a comprehensive dietary assessment. Additional causative factors, such as environmental heavy metals or fluoride exposure, that may have contributed to the clinical syndrome require additional investigation. ${ }^{15}$ Furthermore, a genetic abnormality of vitamin $\mathrm{D}$ biosynthesis, such as a mutation of $250 H D$ (CYP2R1), although extremely rare, needs to be excluded, particularly given the apparent clustering within families. ${ }^{16}$

During the 12-month follow-up of the 29 children described in our study, an additional 307 children were clinically diagnosed and treated for rickets in Naga, making rickets an important public health problem in this region. Fortifying staple foods with vitamin $D$, and promoting the intake of indigenous food sources rich in calcium or vitamin $D$ and calcium supplements may be required to prevent this potentially devastating disease.

\section{CONCLUSION}

Calcipenic rickets is an important problem for children in the Naga region. Several factors made these children at risk. First, the local diet appears to be low in vitamin D, potentially leading to maternal deficiency and low vitamin $D$ levels of newborns and breastfed children. Second, the 
diet also appears to be low in calcium and high in phytates, potentially causing calcium deficiency. Third, breastfeeding is generally prolonged. Fourth, sunlight is relatively low in this region. Treatment with vitamin $D$ and calcium improved symptoms and reversed bone deformities. Further research is urgently required to understand more completely the etiology of this neglected and devastating disease. This understanding can determine the specific interventions required.

Received November 5, 2020. Accepted for publication March 30, 2021.

Published online June 7, 2021.

Acknowledgments: We thank all MAM staff in the Naga region-in particular, San Lin Aung, for his hard work, and John Pettifor, for his critical appraisal of the manuscript.

Financial support: This project was supported by the Planet Wheeler Foundation, the DAK Foundation, the Ripple Foundation, and Shindy Skaar. T. L. is supported by a Hamish Ogston Foundation fellowship. This research was funded, in part, by the Wellcome Trust grant number: 220211. For the purpose of Open Access, the author has applied a CCBY public copyright licence to any Author Accepted Manuscript version arising from this submission.

Authors' addresses: Hein Aung, Medical Action Myanmar, Yangon, Myanmar, E-mail: heinaung@mam.org.mm. Kyaw Soe and Thomas Lamb, Myanmar Oxford Clinical Research Unit, Yangon, Myanmar, E-mails: kyawsoemocru@gmail.com and thomas.lamb@ndm.ox.ac. uk. Frank F. Smithuis, Department of Radiology, Amsterdam UMC Imaging Center, Amsterdam, The Netherlands, E-mail: smithuis@ gmail.com. Moe Wint Aung, Department of Endocrinology, Yangon General Hospital, Yangon, Myanmar, E-mail: moewint@gmail.com. Frank M. Smithuis, Medical Action Myanmar, Yangon, Myanmar, and Myanmar Oxford Clinical Research Unit, Yangon, Myanmar, E-mail: frank.m.smithuis@gmail.com.

This is an open-access article distributed under the terms of the Creative Commons Attribution (CC-BY) License, which permits unrestricted use, distribution, and reproduction in any medium, provided the original author and source are credited.

\section{REFERENCES}

1. World Health Organization, 2019. Nutritional Rickets: A Review of Disease Burden, Causes, Diagnosis, Prevention and Treatment. Geneva, Switzerland: WHO. Available at: https://www.who.int/ publications/i/item/9789241516587. Accessed November 2, 2020.
2. Agarwal A, Gulati D, Rath S, Walia M, 2009. Rickets: a cause of delayed walking in toddlers. Indian J Pediatr 76: 269-272.

3. Pettifor JM, 2004. Nutritional rickets: deficiency of vitamin D, calcium, or both? Am J Clin Nutr 80: 1725-1729.

4. Mendes MM, Hart KH, Botelho PB, Lanham-New SA, 2018. Vitamin $D$ status in the tropics: is sunlight exposure the main determinant? Nutr Bull 43: 428-434.

5. Edidin DV, Levitsky LL, Schey W, Dumbovic N, Campos A, 1980. Resurgence of nutritional rickets associated with breastfeeding and special dietary practices. Pediatrics 65: 232-235.

6. Henderson AH, 1899. Rickets in India and Burma. Ind Med Gaz 34 : 268.

7. Craviari T, Pettifor JM, Thacher TD, Meisner C, Arnaud J, Fischer PR, Rickets Convergence Group, 2008. Rickets: an overview and future directions, with special reference to Bangladesh: a summary of the Rickets Convergence Group Meeting, Dhaka, 26-27 January 2006. J Health Popul Nutr 26: 112-121.

8. Ahmed S, Goldberg GR, Raqib R, Roy SK, Haque S, Braithwaite VS, Pettifor JM, Prentice A, 2020. Aetiology of nutritional rickets in rural Bangladeshi children. Bone 136: 115357.

9. Combs GF, Hassan N, Dellagana N, Staab D, Fischer P, Hunt C, Watts J, 2008. Apparent efficacy of food-based calcium supplementation in preventing rickets in Bangladesh. Biol Trace Elem Res 121: 193-204.

10. Balasubramanian K, Rajeswari J, Gulab A, Govil YC, Agarwal AK, Kumar A, Bhatia V, 2003. Varying role of vitamin D deficiency in the etiology of rickets in young children vs. adolescents in northern India. J Trop Pediatr 49: 201-206.

11. Aggarwal V, Seth $A$, Marwaha RK, Sharma B, Sonkar $P$, Singh $S$, Aneja S, 2013. Management of nutritional rickets in Indian children: a randomized controlled trial. J Trop Pediatr 59: 127-133.

12. Chabra T, Tahbildar P, Sharma A, Boruah S, Mahajan R, Raje A, 2016. Prevalence of skeletal deformity due to nutritional rickets in children between 1 and 18 years in tea garden community. J Clin Orthop Trauma 7: 86-89.

13. Streym SV, Højskov CS, Møller UK, Heickendorff L, Vestergaard P, Mosekilde L, Rejnmark L, 2016. Vitamin D content in human breast milk: a 9-mo follow-up study. Am J Clin Nutr 103: 107-114.

14. The World Bank, 2019. Global Solar Atlas 2.0, Solar Resource Data: Solargis. Available at: https://solargis.com/maps-andgis-data/download/myanmar. Accessed April 25, 2021.

15. Qin X, Wang S, Yu M, Zhang L, Li X, Zuo Z, Zhang X, Wang L, 2009. Child skeletal fluorosis from indoor burning of coal in southwestern China. J Environ Public Health 2009: 969764

16. Thacher TD, Fischer PR, Singh RJ, Roizen J, Levine MA, 2015. CYP2R1 mutations impair generation of 25-hydroxyvitamin D and cause an atypical form of vitamin $D$ deficiency. $J$ Clin Endocrinol Metab 100: E1005-E1013. 